\title{
Celebrities and slackers: A grounded theory of the dynamics of social loafing on student teams
}

\author{
Amy E. Boren, Ph.D. \\ Assistant Professor \\ Texas Tech University \\ Sarahi Morales, M.S. \\ Graduate Student \\ Texas Tech University
}

\begin{abstract}
The purpose of this study was to explore how team members identify the social loafers on their teams and how they explain and manage social loafers' behavior. The participants $(n=49)$ in the study included members of student teams participating in a service project as a part of their coursework. We collected multiple sources of information: in-depth interviews, reflection journals, peer evaluations, and observations of team members interacting. Using attribution theory and status characteristics theory we describe how team members identify social loafer and explain the causes of their behavior. We also explore how those attributions affect team members' interactions with the social loafers. The status of social loafers in the eyes of their teammates affects teammates' willingness to accommodate or reject the social loafer. We identify strategies used by team members to manage the behavior of social loafers. We conclude with recommendations for practice and future research on social loafing.
\end{abstract}

\section{Introduction}

An increasingly common experience of undergraduate students in college classrooms is the oft-dreaded student team project (Payne \& Monk-Turner, 2006; Underwood, 2003). As leadership educators work to foster leadership skills in their students, university campuses see an increase in the use of teams and team projects as 'mini leadership labs' for developing soft skills (Hansen, 2006; Pennington Weeks \& Kelsey, 2007; Rosch, 2015). In spite of its popularity among university instructors, the student team project tends to be negatively viewed by many students, often due to the presence of team members who contribute less than they ought to the team's collaborative work (Aggarwal \& O’Brien, 2008; Jassawalla, Sashittal, \& Malshe, 2009; Coers, Lorensen, \& Anderson, 2009). These 'social loafers' - the non-contributing members of student teams - seem to taint the perceptions of students regarding teamwork. One of the main reasons for students' aversion to working in groups is social loafing of team members (Aggarwal \& O’Brien, 2008; Coers, et al., 2009).

In spite of the negative perception of students toward working on academic projects in teams, the necessity for learning to work in teams is clear. Industry has issued a resounding call for college graduates who are skilled in navigating the complexities of teamwork (Crawford, Lang, Fink, Dalton, \& Fielitz, 2011; Hart Research Associates, 2013, 2015). Hearkening to the 
voice of industry, institutions of higher education have been tasked with the development of teamwork skills in their undergraduates across disciplines. Leadership education provides a platform well suited for not only supporting the development of those teamwork skills, but also for exploring and enhancing students' experiences with teamwork in the academic environment. Improving students' experiences with teamwork in university classrooms can only come by understanding what those experiences are and how they are navigated. In light of the salience of non-contributing team members in influencing students' negative perceptions about teamwork in the classroom, understanding more about the processes surrounding social loafing on student teams would be beneficial. There is insufficient research on students' experiences with social loafing on their teams (Aggarwal \& O'Brien, 2008; Jassawalla, et al, 2009). This study seeks to fill this gap in the literature by examining how team members identify, explain, and manage social loafers on student teams. A grounded theory method was used for this study in order to provide a basis for generating a theory on the team dynamics of social loafing in college classrooms.

\section{Literature Review}

The term social loafing has been defined as "group members who shirk their obligations in the hopes of benefiting from the work of others" (Dommeyer, 2007, p.175). In essence, social loafing refers to the reduced effort of individual team members in completing collaborative work. Social loafers are the quintessential freeloaders who contribute little or nothing to team projects, expect that other team members will make up for their lack of effort, yet still anticipate receiving the same rewards as their more laborious peers (Jassawalla, et al, 2009; Pieterse \& Thompson, 2010).

In an extensive review of the literature on social loafing, Simms and Nichols (2014) carefully deconstruct the phenomenon and identify variables that may increase or decrease social loafing in groups. Their comprehensive work identified areas of interest for both structural and interpersonal interventions to decrease social loafing. For example, enhancing an individual's ability to demonstrate a unique contribution to the group by decreasing group size and ensuring that individual contributions are identifiable by others are effective strategies in reducing social loafing behaviors on teams.

Simms and Nichols' (2014) work integrated work team experiences and student team experiences. Aggarwal and O'Brien (2008) focused their work solely on the experience of student teams. While social loafing on student teams is comprised of structural, interpersonal, and intrapersonal components, Aggarwal and O'Brien (2008) explored primarily the structural components of teams that foster social loafing. Their research indicated that the scope of the team project, the size of the group, and the number of graded peer evaluations required by the instructor all factored into the reduction of social loafing on student teams. Team projects of a smaller scope, such as a semester project divided into smaller deliverables throughout the semester, reduced social loafing. Smaller groups made it less likely that social loafers would emerge. Also, as the number of peer evaluations affecting individual team members' grades in the course increases, the incidents of social loafing on student teams' decrease. 
Jassawalla and colleagues (2009) sought to identify students' perspectives on the antecedents and consequences of social loafing. They found that students identified both individual characteristics of team members and structural dimensions of their teams as contributing to the emergence of social loafers. In particular, social loafers' apathy and disconnectedness negatively influenced other team members' perceptions of the social loafers, and team cohesiveness and higher quality interpersonal relationships appeared to mediate this effect. One finding of interest, though not a focus of research by Jassawalla and colleagues (2009), was that students were loath to report social loafers to their instructors and, except in very extreme cases, students preferred to manage their issues with social loafers within the team, even if it meant an increased workload for team members. Teaching students skills relevant to the management of wayward team members was recommended. This same study also called for additional exploratory research in social loafing on student teams to further elucidate the ways in which students manage social loafers.

Schippers (2014) extended previous research by examining individual differences of team members in compensating for social loafing behaviors. She found that team members with high degrees of agreeableness and conscientiousness were able to compensate effectively for social loafing of other team members. Interestingly, in Schippers' (2014) study, team members engaged in tacit agreements for exculpating social loafers' behaviors. If social loafers demonstrated ability in another context that was deemed valuable by the team members (e.g., performed well in another class and helped teammates with that work), the social loafer was permitted to slack off with impunity. Schippers' (2014) research concluded that the social processes involved in team management of social loafing appear to be complex and are still not well understood.

The aforementioned research studies have been helpful in illuminating the multidimensional nature of social loafing on student teams; but, as Schippers (2014) acknowledges, the complex social processes among team members dealing with social loafing on their student teams have not been adequately addressed.

\section{Theoretical Framework}

Attribution theory (AT) lies at the heart of this current research. AT suggests that people attempt to understand and explain others' behavior - particularly behavior that is unexpected or important - by attributing causal significance to particular factors that may or may not have played a role in influencing the behavior (Martinko, Harvey, \& Dasborough, 2011; Taggar \& Neubert, 2004; Weiner, 1986). In essence, AT posits that people assess the causes of others' behavior based on several factors. One factor they assess is locus of control - in other words, is the cause of the behavior internal to the individual, such as personal effort or intelligence, or is it external to the individual, such as luck? Another factor people examine is controllability determining if the cause of the behavior within the individual's control or not. The final factor people assess is stability - deciding if the cause of the behavior permanent or if it varies over time. (Taggar \& Neubert, 2004; Weiner, 1986).

In an elegant experiment on the role of AT in team members' decisions to help or punish a social loafer, Taggar and Neubert (2004) found that particular personal traits of social loafers -in this case cognitive ability and conscientiousness -- influenced the way that team members of 
the social loafers assessed the causes of the social loafers' behavior. For example, social loafers with low levels of ability but high levels of conscientiousness were viewed positively and attributions for their shortcomings were externalized. On the other hand, social loafers with high levels of ability and low levels of conscientiousness were viewed with anger and the attributions of their failures were placed squarely on their shoulders. Based on the findings from Taggar and Neubert's (2004) research, teams may tend to attribute different causes for social loafing behavior to team members based on the individual traits of the social loafer.

The manner in which the traits of a social loafer are assessed may be influenced by the perceived status of the social loafer on the team. In order to further explicate the process by which social loafers are assessed by their teammates, this current research draws on status characteristics theory (SCT) (Berger, Rosenholtz, \& Zelditch, 1980; Berger, Webster, Ridgeway, \& Rosenholtz, 1986; Bunderson, 2003; Meeusen \& van Dijk, 2016). In essence, SCT posits that groups working toward a particular task organize their expectations and interactions with other group members based on the perceived abilities of the other group members. When a particular group member is perceived to have high ability - based on particular characteristics of importance to the group (Bunderson, 2003) - the group will identify that member as having high status and will defer to that team member in the group. A team member that has been identified as high status will be viewed as valuable and more opportunities for participation will be afforded to the high status member (Meeussen \& van Dijk, 2016).

The key component of SCT relevant to this study is how the high status member is defined and accommodated. In SCT, the characteristics used to define a group member's status are not uniform across different groups; rather, a group member's status relies heavily on the characteristics deemed important by that group and not necessarily on characteristics deemed valuable externally (Berger, et al, 1980). Thus, group members who possess particular physical, social, or other characteristics that are perceived as valuable to the group should achieve high status membership. Based on SCT, teams may value particular characteristics possessed by the social loafer and may exculpate and accommodate the social loafer's limited level of contribution to the team.

\section{Research Questions}

The purpose of this study was to create a theory of social loafing on student teams. Developing a theory surrounding the dynamics of social loafing may serve leadership educators who are using teams in their classes to structure teams in such a way as to minimize social loafing. In our research here, we explore how team members identify the social loafers on their teams, as well as explain and manage their behavior. The following research questions guided this study:

1) How do students identify and describe the social loafer(s) on their student teams?

2) How do students explain the behavior of the social loafer(s) on their student teams?

3) What strategies do students employ to manage the behavior of the social loafer(s) on their student teams? 


\section{Methods/Procedures}

A grounded theory method was used for this study in order to provide a basis for generating a theory on the team dynamics of social loafing in college classrooms. Creswell (2013) recommends the rationale for selecting a particular research design should be driven by the nature of the phenomenon under study. Since the focus of this research was to explore an interactive and fluid social process to generate a theory or model, grounded theory methods were selected. This method engages the researcher in a constant comparative process of data collection and analysis, leading to the synchronization of seemingly disparate concepts into a coherent theoretical model that emerges organically from the data (Corbin \& Strauss, 2015; Glaser \& Strauss, 1967). Our data were analyzed and interpreted, then re-examined and cautiously placed within the paradigm model suggested by Corbin and Strauss (2015). They describe the paradigm model as a weaving tool to help researchers begin linking and looping concepts and their interpretations into a main storyline. The paradigm is composed of three principal elements: the conditions, the actions and interactions, and the consequences or outcomes.

Participants and Context. The participants $(n=49)$ in the study included members of eight student teams participating in a semester-long service project at a local non-profit organization as a part of their undergraduate coursework at a large southwestern university. Participants included 17 females and 32 males.

Following structural recommendations for effective classroom team management (Hughes \& Jones, 2011), the student teams were created and managed using the online Comprehensive Assessment of Team Member Effectiveness (CATME) tool (Loughry, Ohland, $\&$ Woehr, 2014). Prior to the start of the semester, students entered their availability for meeting and working on the project into the CATME scheduling program online. The program then created teams of students whose availability matched most closely. The majority of the student teams had six members, but one team had seven due to the odd number of students participating.

The project was divided into three major deliverables over the course of the semester. After the submission of each major deliverable, students were required to submit a peer evaluation for each member of their teams via the CATME tool. Peer evaluations were both quantitative and qualitative in nature and comprised $15 \%$ of each student's final grade. Quantitative data was averaged among team members for the assigning of a grade and qualitative data was used to anonymously provide helpful feedback to team members concerning their performance.

To collect data, we employed several different strategies: in-depth interviews with participants, reflection journals written by team members about their team experiences, peer evaluations of team members, and observations of team members interacting in different contexts. Using multiple sources of data enhances the credibility and confirmability of the study (Lincoln \& Guba, 1985). Any identifying information of the participants was removed prior to data analysis. 
Interviews. Out of the 49 students involved in the team projects, 13 agreed to participate in the in-depth interviews. We interviewed 8 female students and 5 male students for approximately $30-45$ minutes each. The interviews were semi-structured, providing us with a set of questions to follow, but also leaving us room to explore any substantive issues that arose during each interview (Creswell, 2013).

We asked our participants about their team experiences, including how team members contributed to the semester project and how obstacles to effective team functioning were addressed. We posed questions about their team members' motivation to complete their work on the project and what kinds of leadership they observed. To enhance accuracy of the data, we audio recorded each interview and then transcribed the interviews ourselves. The interview transcripts were then coded by hand (Saldaña, 2013) and were analyzed inductively, allowing themes to emerge organically from the data (Creswell, 2013). We also availed ourselves of double-blind intercoding techniques to reduce any researcher bias in the coding process and enhance credibility and confirmability of the data (Creswell, 2013; Miles \& Huberman, 1994). We engaged in peer debriefing of the coded transcripts to verify our interpretations of the data and to enhance its credibility (Creswell, 2013; Lincoln \& Guba, 1985).

Following each interview, we purposefully engaged in 'memoing' - the writing of detailed notes and observations, as well as personal feelings and reflections, about the interview (Miles \& Huberman, 1994; Saldaña, 2013). The process of memoing helps to ensure our transparency as researchers and reduce bias - thus strengthening the confirmability of the study (Lincoln \& Guba, 1985). Our memos also provided us with contextual clues for coding data and thoughts for discussion during our peer debriefings (Miles \& Huberman, 1994).

We used the data from our interviews to develop themes for illustrating the process of social loafing on student teams. To further refine and polish the themes that emerged from the interview data, we subjected the data to a process of triangulation by comparing it with data we collected from observations and document analysis (Creswell, 2013).

Documents. All 49 members of the student teams were required to write five reflective journal entries on their team experiences and complete three peer evaluations over the duration of the semester project. Of those 49 students, 47 agreed to share their required journals and peer evaluations with us for analysis. In their journals, students described and analyzed their team processes, reflected on their team's effectiveness, and specified how they personally contributed to their team's performance. The journal entries were between one and two pages in length.

Peer evaluations were conducted using the CATME online evaluation system. Evaluations contained Likert-type quantitative ratings of team members on five specific dimensions: contributing to work, interacting with teammates, keeping the team on track, expecting quality, and having knowledge and/or skills. The ratings across the different dimensions were then averaged to create an overall score between one (lowest) and five (highest) for each team member. The evaluations also contained a qualitative component in which the rater could comment freely about his/her evaluation of his/her teammates. 
We analyzed the students' journals and their comments from the peer evaluations using thematic analysis, in which we focused on using the participants' own words to inform the coding and analysis of the students' writings (Silverman, 2014). We used the quantitative portion of the peer evaluations to help guide our interviews and as a point of reference when triangulating the interview, observation, and written data.

Observations. We observed the student teams on four occasions over the course of the semester: in situ while implementing their projects at the non-profit organization and also during team meetings. We designed an observational protocol to facilitate our note taking, diagramming, and reflections during observations (Miles \& Huberman, 1994). We conducted the observations as nonparticipant observers of the student teams (Creswell, 2013); we watched the teams, listened to them interact, and took copious field notes. Prior to beginning our observations of the teams, we made the students aware that we were observing them, explained the purpose of the observations, and asked them if they had any questions. We triangulated the data collected from observations with the document and interview data to confirm or challenge themes that emerged from previous analyses (Creswell, 2013).

Identification of the Social Loafers. Since the term 'social loafer' carries with it rather negative connotations, we believe it is important to explain the process by which the social loafers on these student teams were identified. Our first clue was the reflective journals submitted by the students regarding their team experiences. When multiple members of a team began identifying issues with a particular team member, we made notes about the potential emergence of a social loafer. Our next clue consisted of the first round of peer evaluations. As these are submitted anonymously via the CATME tool, students have a platform for sharing honest information without much fear of reprisal. Using these clues, we focused our observations and interviews on teams that had identified issues with a team member's lack of engagement. In this manner, we were able to discover how teams began identifying particular members as social loafers.

We think it is key to note here that the participants in our research did not ever use the term 'social loafer', nor did we ever use the term 'social loafer' to refer to a team member. Our interviews were structured to engage the participants on the way their team members interacted, the kind of roles they had on the team, why particular team members had those particular roles, and how they worked with members who were not as engaged. We were careful to avoid the use of what could be construed as negative terminology in our interactions with the participants.

We use thick description in this study to detail the context, the content, and the conclusions drawn from the analysis of the data, as well as strengthen the trustworthiness and transferability of the study (Creswell, 2013; Lincoln \& Guba, 1985). In spite of the numerous methods we employed to ensure trustworthiness of the qualitative data presented in this research, it is still important to state that researcher bias cannot be entirely expunged from the research process (Creswell, 2013). We approached this particular research from a constructivist lens and acknowledge our tendency to view social actions from a human relations perspective. We realize that this is a qualitative investigation, describing the particular experiences of our participants, and we do not attempt to make generalizations of the findings of this study to other populations. 


\section{Results/Findings}

Here we present our findings by integrating them into the paradigm; we weave together the components of the theory and present them piece-by-piece within the framework of the paradigm (Figure 1).

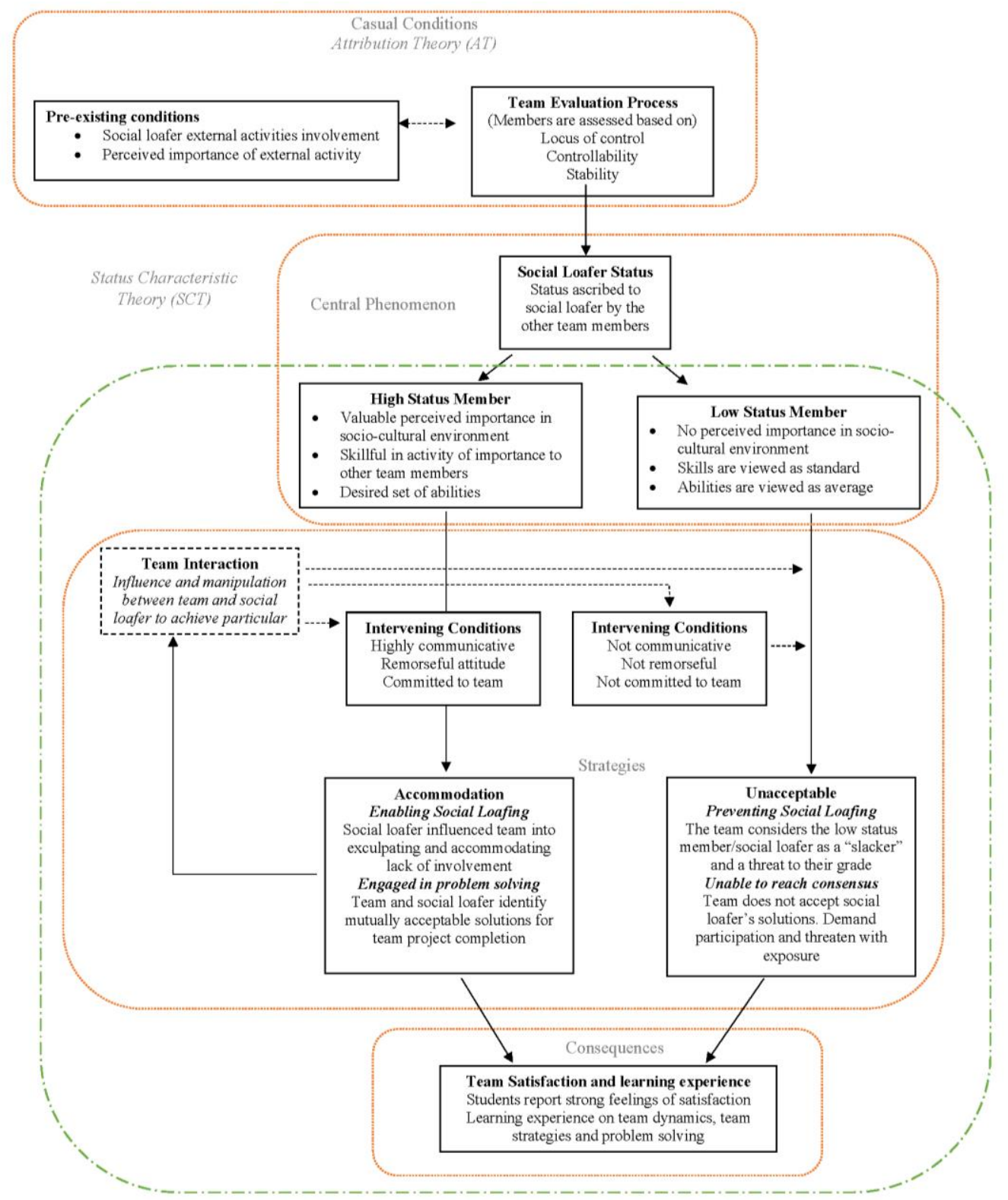

Figure 1. Social loafing paradigm framework

Central Phenomenon. The principal storyline that emerged from the data revolved around the status of the social loafers as ascribed to them by the other team members. Status was related to the perceived importance of the social loafer within the socio-cultural environment of 
the university. This proved to be critical in how team members described the social loafers' lack of participation in teamwork, and whether they chose to accommodate and exculpate the social loafers or block and blame them.

Causal Conditions. The characteristics that lead to the development of the central phenomenon are referred to as causal conditions (Creswell, 2013). In this study, the involvement of the identified social loafers in activities external to their team project that interfered with their participation in the teamwork was a necessary condition. The type of external activities in which the social loafers participated determined the attribution of high or low status to the social loafers in the teams. High-profile activities that brought accolades to the university were necessary for the social loafers to be perceived as high status. Of the nine students identified as social loafers by their team members through peer evaluations, student journals, and interviews, four were involved in competitive activities for the university at the national level, and one was involved professionally in a competitive sport, had achieved national ranking, and had earned a six-figure income through involvement in this sport. While it is rare to come across an undergraduate student who is competing professionally, we still included the team dynamics of this student's team in our analysis. Our interview, document, and observation data from the team did not indicate that this student was more highly regarded than the others who were competing only on university teams. All of the social loafers who participated in competitive activities elicited a sense of pride and admiration in their team members even though their contributions to the team's work were minimal. A team member of a high status social loafer defended his high status teammate's lack of participation:

It's not his fault; he is on the [redacted] team, and we are proud of that. We don't wanna punish him for that. So we are pulling a little more weight, but when you divide it among 6 people, it's not that much. It is a little extra work and he can still contribute by helping out each of us.

The other four social loafers identified on the teams were involved in student organizations, off-campus employment, and a fraternal organization. These activities did not merit the attribution of high status to these social loafers, and were simply seen as normal life activities that needed to be managed. A team member of a low status social loafer described the social loafer's lack of participation:

I guess she's on the student government, but come on; she never has time to show up [for team activities]? I hate to admit this, but you just can't trust or count on her. She's offered to do the entire (final presentation) to make up for all the stuff she's missed, but I do not want to be dependent on her to get it done...there are just some people who are best just sitting on the sidelines.

Strategies. Strategies are the actions implemented by the participants in response to the central phenomenon. The social loafers and their team members engaged in particular strategies of active, reciprocal influence to manipulate each other to achieve particular ends. For the social loafers, these strategies included attempts at gaining status by discussing the importance of their external commitments, how time-consuming those commitments were, and how critical their involvement in these activities was. The goal of these actions was to influence their teammates 
into exculpating and accommodating their lack of involvement - a luxury afforded only to social loafers deemed as high-status by the team. A high-status social loafer described the process from his perspective:

Well, the team project hasn't interfered too much with my schedule. There were some days where we did schedule to go out and work and I had to cancel because I had things that came up. I just told them that, hey, I'm a professional [competitor in sport] and I chose to put in extra practice because there was a big [national competition] that weekend. It was fine. They said I can just go out and work whenever I can.

By emphasizing the importance and national exposure of this competition, this social loafer was able to gain accommodations due to his high-status. Corroborating this perspective, one teammate of this high-status social loafer wrote:

One team member can't be there much but for an understandable reason. We have figured out a plan to get him more involved so that he can actually do some work. We have worked around this schedule so that we can meet when he can more often. I believe that we have overcome this issue and it hasn't created much of a problem so far.

For the teammates of social loafers, strategies varied depending on the status of the social loafer. For the low-status social loafers, teammate strategies entailed discussing how the grade for the project was being jeopardized and how work needed to be distributed equitably and fairly. On two teams with low-status social loafers, threats of exposure to the course instructor were made in the face of non-compliance. The team members of low-status social loafers typically provided them with options for satisfactory engagement, but the social loafers' ideas were not actively pursued for problem solving.

During an observation of a team meeting, we watched as team members negotiated with a low-status social loafer. The subject of this interaction was the allocation of work on the team project. It was late in the semester and the social loafer had not participated in team workdays at the agency as required by the project. He was attempting to negotiate accommodations to further reduce his responsibilities to the team project using the short time frame and his external responsibilities as his justification for additional concessions. The team members had come to a place of unity with respect to the social loafer's contributions and were clear in stating expectations - not a member budged on the decision despite the intense pressure from the social loafer to do so. We overheard the team threaten to expose the social loafer to the instructor if he did not comply with their demands to complete the project at the agency.

This low-status social loafer, whose attempts at gaining concessions had been rebuffed, shared his frustration with us in an interview:

I've told them...this is how I make my living, it's not like I work just for the fun of it. I mean, I like what I do, but it takes a lot of time. I guess they have been pretty understanding, but now I'm under the gun to get my part of the project done. 
For teammates of high-status social loafers, strategies included exploring ways to facilitate the social loafer's participation and engaging the social loafer in active problem solving to identify mutually acceptable solutions for completing the project. Team members of the highstatus social loafers sought ways to work around the social loafer's schedule and proposed concessions such as allowing the social loafer to provide tools for a particular task or edit a document or presentation that was already completed. A team member of a high-status social loafer demonstrated the team's accommodating attitude based on the social loafer's status:

We knew from the beginning that he was going to be out for [competitions] and stuff like that, so he kind of fell behind, and we didn't want him to feel left out. Since he is going to be gone, we can't give him like a big portion of the assignments, but he comes out and helps any individual that needs help [when he can].

In essence, high-status social loafers determined how they would participate in their teams, but low-status social loafers were required to abide by standards set for them by their teammates.

Intervening Condition. The intervening conditions can best be described as mediators that influence the participants' use of strategies. In our research, the sense of remorse and level of expressed interest in the project communicated by the social loafers were the key factors in determining success in their attempts at influencing their teammates. One team member described how the high-status social loafer on his team communicated interest and commitment to his team:

He is always interested. Whenever he comes back [from his competitions] he is always asking what are you guys doing, what do you need, do you need any help... stuff like that. You can tell he feels some kind of remorse for not being around all the activities that need to be done. It has all worked out.

A high-status social loafer on another team discussed his involvement on the team by openly expressing remorse and committing to contribute to the team effort. During the interview, his nonverbal communication suggested a sense of contrition for having missed so much of the team's activities. The pained expression on his face and his tendency to shake his head and look down when discussing his lack of engagement suggested feelings of guilt. He seemed compelled to prove to his teammates that he was intent on contributing to the team's work:

I feel like I could help my team a little more. It's hard with me being gone all the time to [competitions] and traveling to other events. However, when I am there [with the team from class], I feel like I pull a lot of my own weight and contribute to the team as much as I can. I have been bringing most of the tools that our team is going to need and do my best to give $100 \%$ effort when I am there. I don't plan on leaving there thinking that I did not give it my all.

Regardless of their perceived status among their teammates, social loafers who did not display a sense of remorse for their lack of participation or make commitments to the team were eventually blocked from problem solving and blamed for their lack of effort. This process occurred quickly for the low-status social loafers, as demonstrated by this excerpt from the reflection of a teammate of a low-status social loafer: 
We have had one team member neglect to show up to our project workdays to get her hours done. After the first couple of times, we let it go; but after it happened again and she never said anything to us about it, we realized that it actually was a problem that we needed to bring up. All of us [contributing teammates] discussed amongst ourselves as to what to do, and we came to a conclusion. We told her she would have to complete [a particular job] by the end of March or we were going to the teacher.

When it came to high-status social loafers, the process was slow and deliberate - as if the team members struggled with integrating a negative characteristic into the positive mental model they had erected around this high-status individual. One team member of a high-status social loafer had consistently supported the social loafer on his team and advocated for concessions for him while he competed nationally for a university team. Yet when the season ended for the social loafer's competitions, and he still did not contribute to the group project, the ire of his loyal teammate was kindled. In the final, scathing peer evaluation of the social loafer, the offended teammate commented:

After the [competitive] season ended, we saw that he was not accountable to our team. Many times we did not know where he was because he wouldn't respond to the group text. This infuriated the rest of us group members, because he obviously did not take our group project seriously. I am not the kind of person to let others cheat off of me all semester by doing the whole project for them. I don't like lazy people.

Consequences. The actual or anticipated outcomes of the strategies comprise the consequences in grounded theory (Corbin \& Strauss, 2015). The outcomes experienced by the participants in our study included the level of satisfaction with the team project, insight about engaging with others in teamwork, and an enhanced awareness of the dynamics that factor into managing a team in other contexts. Overall, both the social loafers and their teammates gained insight from the team experience.

Interestingly, most students reported a strong feeling of satisfaction with the project even the low status social loafers. Out of a highest possible rating of five, the highest score was 5.0 and the lowest was 3.0 (provided by one of the low-status social loafers). The average rating across all 49 participants was 4.67 .

In his final evaluation of the project, one of the low-status social loafers reflected on his experience with the team and the dynamics of making teamwork successful:

I actually had a good time doing this team project towards the end. We did finally come together to get things finished up and tightened up. I would say to any future group members, including myself, that they should not procrastinate on a project - just get it done and don't make excuses.

A different team member wrote, "I learned a lot about myself and how to work well in teams." Another student commented, "This was a valuable learning experience that I will never forget. I am so thankful for the opportunity to learn to work effectively with others. Our team really did very well." 
Demonstrating an awareness of the team dynamics involved in completing a project, one team member reflected:

This semester project was a constant negotiation about the elements that go into team commitment. We were able to be productive in defining tasks and following them up to reach our team goals. The harmony we experienced was from my team members being appreciative of me as much as I was appreciative of them, which led to our success.

One student thought ahead to practical application of the team management skills in future employment contexts:

This team project was a good experience overall, though (a low-status social loafer) could have been better. I have learned skills that I will definitely be taking into my future career. It allowed me the opportunity to see how working with a group of people turned out. I feel like I have matured this semester into a more well-rounded leader.

By working on a semester-long project on a team of people with varied backgrounds, interests, skills, and schedules, participants were able to learn from the strategies they employed to complete the project as a team and even extrapolate their learning to future situations.

\section{Conclusions}

The purpose of this study was to create a theory of social loafing on student teams. According to Simms and Nichols (2014), social loafing can occur in any given team activity; and once it is confirmed, researchers should focus on investigating the individuals and context in which it occurs. In exploring how team members identify the social loafers on their teams, we discovered the identification of social loafers is complicated by the perceived status of the social loafer; a social loafer deemed to have high status is not viewed as a loafer, but rather an important personage to be accommodated. A social loafer deemed to have low status is viewed as a problem to the team that must be managed through draconian tactics, such as threats. In this study, status was bestowed upon the social loafers if they participated in a very visible competitive activity that was esteemed as valuable by the team members. Social loafers were not afforded high status if they participated in activities that were considered to be ordinary ventures that fell within the scope of daily life. The use of individual traits by students to classify social loafing in this study is similar to the findings by Taggar and Neubert (2004).

The Status Characteristics Theory (SCT) suggests that groups working on particular tasks identify team members based on their perceived abilities (Bunderson, 2003). The status of the social loafers influenced the way the other team members chose to explain and manage the social loafers' behavior toward the team. Social loafers considered to be high status by their team members were consulted about alternative activities they could undertake to fulfill their obligations to the team. Their team members were willing to accommodate the needs of the high status social loafers.

Using attribution theory helps to illuminate the decision-making processes of teammates of high status social loafers to accommodate their lack of engagement. In attribution theory, 
behavioral causes are assessed for locus of control, controllability, and stability (Taggar \& Neubert, 2004). In our research, the team members attributed the high status social loafers' nonparticipation in the team project as an external occurrence that could not be helped; these occurrences were out of the control of the social loafers and were considered to be more important than the team project. Throughout this study, teammates of high status social loafers referenced the competitive season as the reason for the loafers' nonparticipation - if it weren't for the season, the high status social loafer would most certainly be engaged in the team activities. In other words, this was a variable behavioral state. High status social loafers were able to retain their elite status as long as they demonstrated contrition for their lack of participation and communicated an interest in the status of the project.

Social loafers with low status were not consulted about alternatives; rather, they were given mandates to fulfill by their team members in order to remain in good standing on the team. If low status social loafers balked at the demands, their teammates delivered threats of exposure of their irresponsible behavior to the instructor. Generally, team members were not accommodating in managing the low status social loafers' behavior. Even when low status social loafers expressed contrition and interest in the project, their team members maintained an attitude of inflexibility and disapproval.

Attribution theory also helps to explain the decision-making processes of teammates of low status social loafers. Team members attributed the low status social loafers' lack of engagement in the project as a personal choice that preferred one activity to another; in other words, the cause of the behavior was internal. The preference of the other activity over team activities was viewed as something that was within the control of the social loafers; in essence, these social loafers were seen as purposefully shirking their responsibilities to the team. Teammates saw the low status social loafers' lack of participation as a stable personal characteristic, not a time-bound malady but a character flaw in the individual. Because of this view of the low status social loafers as irresponsible, unorganized, or just lazy, their teammates tended to be punitive in their dealings with them. The low status social loafers were ascribed the blame for their lack of participation and had a difficult time managing their relationships with the other team members.

In spite of the challenges of navigating the complexity of the team dynamics throughout the course of the semester, all participants experienced a sense of satisfaction resulting from the conclusion of the team project. Many discussed the importance of the skills they learned working on a project team over the course of a semester. Others reflected on the applicability of their newly discovered team skills to new and different contexts. Yet others pondered on how their behavior could have been different and left with recommendations for other teams. It may be that these challenging team experiences serve as a form of productive struggle for the students. These experiences encourage their personal and interpersonal growth.

\section{Recommendations for Practice and Future Research}

As leadership educators continue to use teams to enhance the application of leadership skills taught in the classroom, we need to explore how to maximize our students' ability to effectively navigate and manage the complex social dynamics of student teams. One way to 
assist students is by structuring the teams based on student schedules to help facilitate cooperation outside of class time. Leadership professors should help prepare students for teamwork by creating assignments in which the roles of each team member, the specific duties included in those roles, and dates for completion of associated tasks are defined and submitted to the instructor. This may help to curb some of the more egregious social loafing behavior by providing each team the opportunity to negotiate their roles and responsibilities up front before the work begins. This exercise may also assist in providing all team members a voice in determining how they will be involved with the team.

From a leadership development perspective, our research has demonstrated that negotiations - both tacit and direct - occur often on student teams. Providing instruction on negotiation skills for student teams could help prepare them for negotiations with their team members and could assist students in more successfully navigating stressful situations on their teams.

Leadership educators could also work with students on the development of political skill to enhance their effectiveness in negotiating with their team members. Political skill has been identified as a key variable in workplace satisfaction and success (Buchanan \& Badham, 2008; Ferris, Treadway, Perrewé, Brouer, Douglas, \& Lux, 2007). Team contexts provide an opportune learning platform for political skill development and use.

We recommend that additional research exploring social loafing on student teams be conducted. While we took careful steps to ensure the trustworthiness of our grounded theory study, we do recognize it is bound to the context in which it was conducted. We suggest replicating this study across multiple settings of student team projects to determine if the status of the social loafer is present in other types of team learning activities.

We recommend exploring the social loafers more deeply. For example, it would be interesting to explore the level of political skill of the social loafers: Are high status loafers able to more effectively persuade their team members into believing that their external activities are more valuable than the team activities? Do low status loafers lack political skill? Or, are these merely dependent upon the attribution of value placed on the external activity by the other team members? These questions merit additional scrutiny.

We also recommend that research on social loafing be conducted on different types of teams. The students in our research were rather homogenous - there was little racial or age diversity on the teams. Exploring concepts like status characteristics theory with a more diverse group of students could yield additional depth in understanding how status is ascribed. Also, exploring issues of status with teams in which non-traditional students are present could help to further refine the process of ascribing status on student teams.

Finally, we suggest research employing a randomized experimental design to examine more deeply the issues of status and blame on student teams using team member expectations, political skills, and identity. By exploring the political skills social loafers possess, how they perceive themselves, and how those variables interact with team members' expectations, we could gain additional insight into the team dynamics of social loafing. 


\section{References}

Aggarwal, P., \& O'Brien, C. L. (2008). Social loafing on group projects: Structural antecedents and effect on student satisfaction. Journal of Marketing Education, 30(3), 255-264. doi:10.1177/0273475308322283

Berger, J., Rosenholtz, S.J., \& Zelditch, M. (1980). Status organizing processes. Annual Review of Sociology, 6, 479-508. doi:10.1146/annurev.so.06.080180.002403

Berger, J., Webster, M., Ridgeway, C., \& Rosenholtz, S.J. (1986). Status cues, expectations, and behavior. In E. Lawler (Ed.), Advances in group processes, Vol. 3 (pp. 1-22). Greenwich, CT: JAI Press.

Buchanan, D.A., \& Badham, R.J. (2008). Power, politics, and organizational change (2 ${ }^{\text {nd }}$ ed.). Thousand Oaks, CA: Sage.

Bunderson, J.S. (2003). Recognizing and utilizing expertise in work groups: A status characteristics perspective. Administrative Science Quarterly, 48(4), 557-591.

Coers, N., Lorensen, M., \& Anderson, J.C. (2009). Case study: Student perceptions of groups \& teams in leadership education. Journal of Leadership Education, 8(1), 93-110. doi:10.12806/v8/i1/rf1

Corbin, J., \& Strauss, A. (2015). Basics of qualitative research: Techniques and procedures for developing grounded theory. Thousand Oaks, CA: Sage.

Crawford, P., Lang, S., Fink, W., Dalton, R., \& Fielitz, L. (2011). Comparative analysis of soft skills: What is important for new graduates? Washington, DC: Association of Public and Land-grant Universities.

Creswell, J.W. (2013). Qualitative inquiry \& research design: Choosing among five approaches ( $3^{\text {rd }}$ ed.). Thousand Oaks, CA: Sage.

Dommeyer, C. J. (2007). Using the diary method to deal with social loafers on the group project: Its effects on peer evaluations, group behavior, and attitudes. Journal of Marketing Education, 29(2), 175-188. doi:10.1177/0273475307302019

Ferris, G.R., Treadway, D.C., Perrewé, P.L. Broer, R.L., Douglas, C., \& Y Lux, S. (2007). Political skill in organizations. Journal of Management, 33(3), 290-320.

Glaser, B.G., \& Strauss, A.L. (1967). The discovery of grounded theory: Strategies for qualitative research. New Brunswick, NJ: Aldine Transaction. 
Hansen, R.S. (2006). Benefits and problems with student teams: suggestions for improving team projects, Journal of Education for Business, 82(1), 11-19. doi:10.3200/JOEB.82.1.11-19

Hart Research Associates. (2013). It takes more than a major: Employer priorities for college learning and student success. Washington, DC: Hart Research Associates.

Hart Research Associates. (2015). Falling short? College learning and career success. Washington DC: Hart Research Associates.

Hughes, R.L., \& Jones, S.K. (2011). Developing and assessing college student teamwork skills. New Directions for Institutional Research, 149, 53-64. doi:10.1002/ir.380

Loughry, M.L., Ohland, M.W., \& Woehr, D.J. (2014). Assessing teamwork skills for assurance of learning using CATME Team Tools. Journal of Marketing Education, 36(1), 5-19. doi:10.1177/0273475313499023

Martinko, M.J., Harvey, P., \& Dasborough, M.T. (2011). Attribution theory in the organizational sciences: A case of unrealized potential. Journal of Organizational Behavior, 32(1), 144149. doi:10.1002/job.690.

Meeussen, L., \& van Dijk, H. (2016). The perceived value of team players: A longitudinal study of how group identification affects status in work groups. European Journal of Work and Organizational Psychology, 25(2), 200-2011. doi:10.1080/1359432X.2015.1028378.

Merriam, S. B. (1998). Qualitative research and case study applications in education. San Francisco, CA: Jossey-Bass.

Payne, B.K., \& Monk-Turner, E. (2006). Students' perceptions of group projects: The role of race, age, and slacking. College Student Journal, 40(1), 132-139.

Pennington Weeks, P., \& Kelsey, K. (2007). Student project teams: Understanding team process through an examination of leadership practices and team culture. Journal of Leadership Education, 6(1), 209-225. doi:10.12806/v6/i1/rf11

Pieterse, V., \& Thompson, L. (2010). Academic alignment to reduce the presence of "social loafers" and "diligent isolates" in student teams. Teaching in Higher Education, 15(4), 355-367. doi:10.1080/13562517.2010.493346

Rosch, D. (2015). Effects of classroom-based team experiences on undergraduate student leadership development: When practice does not make perfect. Journal of Leadership Education, 14(3), 104-118. doi:1012806/V14/13/R7

Simms, A., \& Nichols, T. (2014). Social loafing: A review of the literature. Journal of Management Policy and Practice, 15(1), 58-67. 
Schippers, M.C. (2014). Social loafing tendencies and team performance: The compensating effect of agreeableness and conscientiousness. Academy of Management Learning \& Education, 13(1), 62-81. doi:10.5465/amle.2012.0191

Taggar, S., \& Neubert, M. (2004). The impact of poor performers on team outcomes: An empirical examination of attribution theory. Personnel Psychology, 57(4), 935-968. doi:10.1111/j.1744-6570.2004.00011.x

Underwood, J.D.M. (2003). Student attitudes towards socially acceptable and unacceptable group working practices. British Journal of Psychology, 94(3), 319-337. doi:10.1348/000712603767876253

Weiner, B. (1986). An attributional theory of motivation and emotion. New York: SpringerVerlag.

\section{Author Biographies}

Amy E. Boren is an assistant professor in the Department of Agricultural Education \& Communications at Texas Tech University. Her research and teaching efforts include service learning and leadership development. She can be reached at amy.boren@ttu.edu.

Sarahi Morales is a doctoral student in the department of Agricultural Education \& Communications at Texas Tech University. Her research interests include experiential learning and program development. She can be reached at sarahi.morales@ttu.edu. 